\title{
ADDENDA AL CATÁLOGO FLORÍSTICO DE LA PROVINCIA DE MÁLAGA
}

\author{
A. Asensi y B. Díez Garretas*
}

\section{RESUMEN}

Se incluyen nuevas citas, no mencionadas en nuestra anterior aportación (ASENSI \& DíEz, 1975:7-24) y que han sido recientemente confirmadas.

\section{SUMMARY}

New records, wich have been recently collected and were not reported in our latest article (ASENSI \& DfEz, 1975:7-24), are included.

\section{PTERIDOPHYTA \\ ASPLENIACEAE}

Asplenium trichomanes L., Sp. Pl. 1080 (1753)

subsp. quadrivalens D. E. Meyer, Ber. Deutsch. Bot. Cres. 74:456 (1962).

UF04 Reales de Genalguacil, Sierra Bermeja de Estepona, 11-VI-75, Asensi et Hernández (Herb. MÁlAGA 2766). Ibid., 16-V-76, Asensi et Diez Garretas (Herb. MALAGA 3565).

UF35 Sierra de Ojén, 29-X-77, Asensi et Diez (Herb. MÁlAGA 4309).

Pleurosorus hispanicus (Cosson) C. V. Morton, Bull. Soc. Bot. Fr. 106:223 (1959). Ceterach hispanicum (Cosson) Mett.

UF45 Sierra de Mijas, carretera que va desde Mijas hasta Coín, 3-IV-76, Asensi et Díez Garretas (Herb. MALAGA 3482).

\section{CONIFEROPSIDA \\ CONIFERALES \\ CUPRESACEAE}

Juniperus communis L., Sp. Pl. 1040 (1753)

subsp. nana Syme in Sowerby, Engl. Bot. ed. 3, 8:275.

I. sibirica Burgsd.

J. nana Willd.

UF26 Falda de la Torrecilla, 10-II-76, Asensi et Díez Garretas (Herb. MÁLAGA 3991).

(*) Departamento de Botánica. Facultad de Ciencias. Universidad de Málaga. 


\section{TAXOPSIDA}

TAXALES

TAXACEAE

Taxus baccata L., Sp. Pl. 1040 (1753).

En el comentario crítico de la corología de esta especie (AsEnsi \& Díez, 1975: 7-24), dudábamos de su existencia en la Serranía de Ronda, donde había sido denunciada por Ceballos y Vicioso (1933:145). En la actualidad hemos podido localizar algunos ejemplares de porte rastrero y muy protegidos en grietas de rocas.

UF26 La Torrecilla, Serranía de Ronda, 10-II-1976, Asensi et Diez Garretas (Herb. MÁLAGA 3911).

\section{BIBLIOGRAFIA}

Asensi, A. \& Díez, B. 1975. Catálogo florístico de la provincia de Málaga. I. Selaginellaceae-Ephedraceae. Act. Bot. Malacitana, 1:7-24. Málaga.

Boissier, E. 1839-45. Voyage botanique dans le midi de l'Espagne. vol. 2. París.

Ceballos, L. \& Vicioso, C. 1933. Estudio sobre la vegetación y flora de la provincia de Málaga. Inst. For. Inv. Exp. Madrid.

Tutin, T. G. \& col. 1964. Flora Europaea. vol. I. Cambridge.

(Recibido el 28 de agosto de 1977) 